\title{
Pedaleando con Lefebvre por el carril-bici de Sevilla: por qué no debemos presuponer que las infraestructuras públicas restringen necesariamente el derecho a la ciudad
}

\author{
Pedalling with Lefebvre along the bike-lanes of Seville: \\ why we should not assume that public infrastructures \\ necessarily restrict the right to the city
}

\author{
Pedro Malpica ${ }^{1}$ \\ Fecha de recepción: 01-02-2021 - Fecha de aceptación: 17-05-2021 \\ Hábitat y Sociedad (ISSN 2173-125X), n. ${ }^{\circ}$ 14, noviembre de 2021, pp. 263-286. \\ https://doi.org/10.12795/HabitatySociedad.2021.i14.14
}

\section{Summary}

The notion —clearly inspired by Lefebvre- according to which public works have per se a coercive character that curtails the inhabitants' right to the city, should not be applied when evaluating certain infrastructures which actually improve the livability of the urban space, such as those promoting urban cycling. Considering this possible error, it is necessary to examine the repeated exceptions that Lefebvre himself enunciates throughout his work when he characterizes some types of urban intervention that, when fulfilling certain conditions, contribute to the resignification and reappropiation of urban space. We here pursue not only to enumerate these notes by Lefebvre, but to illustrate them taking as a model an urban intervention of great repercussion such as the infrastructure for the promotion of urban cycling in the city of Seville in the first decade of the 21st century, and applying such Lefebvrian contributions to its characteristics. In the confrontation of the different space-producing strategies, some infrastructures - such as the one addressed in this case study - guarantee the right to the city, instead of being, as could be argued from a superficial reading of Lefebvre's analysis, an element that restricts that right.

\section{Key words}

Production of space; Urbanism; Urban infrastructure; Transportation; Urban cycling

\section{Resumen}

La noción, de clara inspiración lefebvriana, según la cual las obras públicas tienen per se un carácter coactivo que cercena el derecho a la ciudad de los habitantes, no debería aplicarse a la hora de valorar ciertas infraestructuras, tales como las que promueven el ciclismo urbano, que suponen en efecto un fomento de la habitabilidad de la ciudad. Ante este posible error, se hace necesario examinar las reiteradas excepciones que el propio Lefebvre enuncia a lo largo de su obra cuando caracteriza aquellas intervenciones urbanísticas que, al cumplir ciertas condiciones, favorecen la resignificación y reapropiación del espacio urbano. Nos proponemos no solo enumerar dichos apuntes de Lefebvre, sino ilustrarlos tomando como modelo una intervención urbanística de gran repercusión como fueron las dotaciones de promoción del ciclismo urbano en la ciudad de Sevilla en la primera década del siglo xxı y aplicando a sus características dichas contribuciones lefebvrianas. En la pugna por las estrategias de producción del espacio, infraestructuras como la abordada en este estudio de caso garantizan el derecho a la ciudad, en lugar de resultar, como podría argüirse desde una lectura superficial del análisis de Lefebvre, un elemento que restrinja ese derecho.

\section{Palabras clave}

Producción del espacio; Urbanismo; Infraestructuras urbanas; Transporte; Ciclismo urbano

1 Universidad de Sevilla. E-mail: ptmalpica@us.es. ORCID: https://orcid.org/0000-0002-0309-7229. 


\section{Introducción}

Lefebvre plantea a finales de los años sesenta del pasado siglo una aproximación a la ciudad que supone una ruptura con los enfoques hegemónicos existentes hasta entonces en la Sociología Urbana, fundamentalmente el de la Escuela Ecológica de Chicago (Gottdiener y Hutchison, 2011, p. 14). Lefebvre relanza la economía política urbana al incluir la geografía, la planificación urbanística, la economía política y la sociología en el análisis de la ciudad; e introduce la idea del espacio como componente de organización social, recuperando la función de la ciudad que Marx, de forma más implícita, y Engels, expresamente, señalaron: un espacio en el que se dan relaciones sociales específicas a través de las cuales se configura un tipo de sociedad (ob. cit., pp. 80-81). Su teoría influyó en el curso que tomaría la Sociología Urbana posteriormente, siendo precursor del enfoque socioespacial que surgirá posteriormente en Estados Unidos y antecedente de autores como Castells, en particular en la primera fase de su producción científica. La contribución de Lefebvre a la "ciencia de la ciudad" — por utilizar su propia denominación- se revela imprescindible en las ciencias sociales, el urbanismo y la arquitectura, y su análisis sobre la producción social del espacio ejerce desde entonces un gran ascendiente en los estudios sobre lo urbano. Precisamente por su gran influencia, es preciso evitar que se interpreten como axiomas lefebvrianos posibles lecturas someras de su obra que no recojan en profundidad el análisis que dicho autor realiza sobre el carácter constrictivo que habitualmente caracteriza a las obras públicas, ante cuya inconveniencia suele expresar extrema cautela, cuando no oposición.

Es cierto que Lefebvre constata que el espacio urbano es producido con fines coercitivos por entidades públicas y privadas de gran influencia. El Estado usa el espacio para el control social: las instituciones lo planifican y lo administran. Asimismo, el sector inmobiliario, mediante el segundo circuito del capital, invierte en suelo, interviene en la decisión del uso que se destinará al mismo y promueve el crecimiento de la ciudad; en este proceso, no solo el sector inmobiliario sino todo tipo de empresas diversas influyen en el espacio de la ciudad y lo configuran. Lefebvre alerta del irrefrenable proceso de urbanización de su tiempo, marcado por la industrialización y la productividad capitalista, que no solo amplía la ciudad hasta invadir el ámbito rural, sino que despoja a la ciudad tradicional de su vida social, destruye la comunidad y repercute de forma nociva en las mentes de sus habitantes-empleamos aquí el término "habitante" para referirnos a la persona que vive (en) la ciudad, a pesar de la reserva que sobre el mismo expresa Lefebvre (2013, p. 394) —. La funcionalidad, la segregación y la mercantilización son los principios que rigen la administración del ámbito urbano y desposeen a las personas del espacio y tiempo que habitan: "El doble proceso de industrialización y urbanización pierde todo sentido si no se concibe a la sociedad urbana como meta y finalidad de la industrialización, si se subordina la vida humana al crecimiento industrial." (Lefebvre, 1978, p. 165). Ante este envite, los individuos y la práctica social que realizan en la ciudad con independencia de lo establecido por las élites -individuos y prácticas que también forman parte de manera inseparable del proceso de urbanización-suponen un factor de resistencia a esta transformación de la ciudad (Lefebvre, 1978; 1983; Costes, 2012). Existen, por tanto, definiciones del espacio urbano realizadas desde intereses contrapuestos por parte de quienes en él se si- 
túan y sobre él inciden, por lo que el fenómeno y el espacio urbano no son solo el objeto de las diversas acciones sino también escenario de las mismas: son, en palabras de Lefebvre (1983, p. 93), "lugar y terreno donde se enfrentan las estrategias" "que sobre la ciudad distintos agentes emprenden. En esta disputa se dirime la ciudad resultante, y Lefebvre toma partido por aquella que, en detrimento de los intereses del Estado y de las empresas, garantice los derechos de sus habitantes. " $L o$ urbano solo puede confiarse a una estrategia que pusiera en primer plano la problemática de lo urbano, la intensificación de la vida urbana, la realización efectiva de la sociedad urbana" (Lefebvre, 1978, p. 104).

Este marco no está exento de excepciones, como se encarga de señalar el mismo Lefebvre. De obviarse estas en una lectura superficial de su obra, se podría considerar que toda intervención pública en el espacio urbano se contrapone por defecto al disfrute de la ciudad por parte de las personas; y que, por tanto, toda infraestructura urbana coartará, por definición, la libertad y la espontaneidad de la población en general. Desde esta falsa premisa, en lo tocante a las políticas municipales para la promoción del ciclismo urbano, podría afirmarse que la construcción de carriles-bicis por parte de las entidades locales deberá catalogarse por defecto como una iniciativa lesiva al derecho a la ciudad - una presunción aplicable a otras innovaciones urbanísticas de diversa naturaleza- En cambio, una lectura atenta a la obra de Lefebvre nos descubre que, muy al contrario, dicho autor reconoce la posibilidad de un urbanismo favorable a los derechos de los habitantes, e incluso caracteriza a lo largo de su producción científica qué requisitos debe cumplir una obra pública para favorecer la habitabilidad del espacio urbano. Dichos aspectos son en ocasiones reconocibles en ciertas intervenciones municipales, como la que nos ocupa en caso de estudio que analizaremos aquí: precisamente un reciente y bien estudiado caso de intervención para la promoción del ciclismo urbano, como fue el que se desarrollado a partir de 2004 en la ciudad de Sevilla.

El presente artículo, por tanto, se propone realizar una lectura analítica de la teoría de Lefebvre con el objeto de contrastar los rasgos excepcionales que dicho autor, de forma no necesariamente sistemática, señala a lo largo de su obra para caracterizar aquellas intervenciones de obra pública que no solo no conculcan el derecho a la ciudad de las personas, sino que contribuyen a la habitabilidad del espacio urbano. Para ello acudiremos al método de estudio de caso, examinando, como acabamos de señalar, la implementación de la red de carriles-bici y de otras dotaciones ciclistas que tuvo lugar en la capital andaluza en la primera década del presente siglo, comparando diversos aspectos de la génesis, desarrollo y características de dichas obras públicas con los criterios con los que Lefebvre a lo largo de su obra distingue a las intervenciones urbanísticas que, lejos de conculcar el libre disfrute del espacio urbano, lo promueven y fortalecen. Para el estudio de dicho caso realizaremos un análisis secundario de los resultados de la investigación sobre ciclismo urbano en Sevilla realizada por mí mismo (Malpica, 2020) con metodología eminentemente cualitativa, incluyendo análisis bibliográfico y de fuentes documentales, método etnográfico, observación participante, entrevistas semi-estructuradas y grupos discusión. El trabajo de campo de la muestra estructural de grupos de discusión fue subvencionado por la Consejería de Fomento y Vivienda de la Junta de Andalucía dentro de la convocatoria I+D+i de 2013-2014.

El presente artículo abordará en un primer momento el análisis de Lefebvre sobre la disputa por la producción del espacio urbano, inte-

2 En cursiva en el original. 
resándonos particularmente por el papel que la ciencia y de la técnica deberían detentar en dicha pugna espacial (y comparando los criterios que deseablemente para Lefebvre debía aplicar la ciencia urbana con algunas de las características que distinguieron a la implementación de las infraestructuras ciclistas en el caso sevillano); posteriormente, nos detendremos a analizar la teoría de Lefebvre sobre movilidad urbana, cotejando algunos de sus aspectos relevantes con las especificidades de la locomoción ciclista como productora de un nuevo espacio urbano; y finalmente, contrastaremos las recomendaciones lefebvrianas sobre los procesos de intervención en obra pública con algunos aspectos de nuestro caso de estudio tales como su carácter participativo, su contribución a las necesidades de sectores desatendidos, su relación con distintos niveles de apropiación del espacio urbano o su positivo impacto medioambiental.

\section{La disputa por la producción del espacio urbano}

Lefebvre reivindica el derecho a la ciudad y hace un llamamiento a la toma de conciencia por parte de la población, así como a su participación activa en los procesos que determinan el futuro de las ciudades. De esta forma la ciudad podrá alcanzar su verdadero potencial: ser producida por y para la sociedad urbana. El análisis realizado por Lefebvre en torno a la producción social del espacio no se limita a proporcionarnos un marco mediante el cual interpretar desde una nueva perspectiva la función de las infraestructuras urbanas, de los administradores públicos que las definen y del conocimiento técnico y científico que se aplica en el proceso de planificación e implantación de las mismas: también nos permite concebir el modo en el que un individuo se sitúa y actúa en la vía pública, percibe los elementos urbanos y a otros agentes móviles, e interacciona con estos y aquellos; es decir, cómo incide sobre el espacio circundante, sobre sus infraestructuras, y sobre las políticas y las normas que lo ordenan. El individuo puede además ser un agente de tensión entre las infraestructuras y el espacio social donde estas se sitúan, o entre las normas y el espacio social que estas regulan. Todo ello, en lo referente al propósito del presente texto, supone un marco adecuado para el desarrollo de algunas características de la conducción ciclista y para profundizar en la relación del usuario de la bicicleta con el espacio de la ciudad en la que se sitúa y transita, y con las normas que regulan su movimiento. En el análisis del ciclismo urbano, como en el de cualquier otro fenómeno en el que concurra el factor del espacio social, Lefebvre nos invita a interpretar que la práctica personal es una alternativa al concepto de espacio tal y como es construido por el poder y sus estrategas, sean estos legisladores, arquitectos, urbanistas, gestores o políticos: un método efectivo de transformar el espacio, desde una dimensión predefinida e inerte, a otra dinámica y vivida.

Para Lefebvre la actividad social no se limita a una interacción entre individuos, sino también entre estos y el espacio en la que dicha interacción tiene lugar. El espacio se vincula así a la actividad social de dos formas: influye - según es producido por instituciones y corporaciones- en el comportamiento de las personas y es a su vez configurado por la interacción humana a través del uso social que se realiza del espacio mismo. El espacio, por tanto, también es producido por los individuos en su práctica diaria, al relacionarse no solo en el espacio, sino con él. De la misma forma que las instituciones públicas y el mercado 
intervienen de forma decisiva sobre el espacio, los individuos lo habitan y hacen del mismo un uso cotidiano que resulta fundamental en la producción social del mismo, generalmente utilizándolo de forma distinta a cómo se había concebido por parte de instituciones y empresas. Por tanto, al mismo tiempo que el espacio, tal y como fue determinado por parte de entidades públicas y privadas, supone un factor de influencia en el uso que de él hacen los individuos, estos no encuentran en él un límite inamovible, sino que pueden modificarlo. A través de diferentes aproximaciones al espacio, los distintos agentes establecen una suerte de contienda en relación con la producción del espacio. Debido a las diferencias entre ambos tipos de producción, generados desde intereses opuestos (no circunscritos en la obra de Lefebvre, a diferencia del marxismo clásico, al conflicto de clase), se produce entre ellos un conflicto de gran impacto social.

En Lefebvre, la vivencia de la ciudad no consiste en que el individuo se ciña a estar en el espacio urbano que lo rodea, ni a limitarse a contemplarlo "como un cuadro, un espectáculo, o un espejo", sino que implica una acción sobre el mismo: "Sabe que tiene un espacio y que está en ese espacio. No disfruta solo de una visión, de una contemplación o de un espectáculo: actúa y se sitúa en el espacio como participante activo" (Lefebvre, 2013, p. 331). Será importante recordar, cuando algo más adelante desarrollemos la incidencia del individuo en su espacio circundante, el carácter de proximidad y de inmediatez de esta práctica cotidiana. Desde este punto de vista, la práctica vivida ha de entenderse como la acción sobre el espacio a través de una relación directa y cotidiana del individuo con el espacio urbano más próximo y sus elementos:

Lo urbano (la vida urbana, la vida de la sociedad urbana) implica ya una sustitución del contrato por la costumbre [...]. El uso, en lo urbano, consta de costumbres, las cuales tienen más influencia que el contrato. El empleo de objetos urbanos (acera, calle, travesía, alumbrado, etc.) es habitual, no contractual [...] (Lefebvre, 1983, pp. 183-184).

La vida urbana, así, puede reapropiarse de la ciudad definida por las instituciones; sus habitantes pueden resignificarla. Lefebvre señala en cierto punto que son aquéllos que no gozan de prerrogativas quienes desde una situación de desposeimiento o frustración pueden ser más activos en este ejercicio de reapropiación. El interés por lo urbano y la disposición a intervenir en lo urbano podrían ser más acusados en los individuos que estén en situación de carencia o exclusión (Lefebvre, 1978, p. 119). No será aventurado, como veremos más adelante, considerar al ciclista urbano como uno de los agentes que cumplen con estas características, especialmente en el contexto del transporte y en condiciones de ausencia de medidas de protección o de fomento del uso de la bicicleta. A este respecto, Lefebvre señala que no serán las políticas públicas de integración, sino la auto-organización de los individuos que componen la sociedad urbana, quienes promuevan esa intervención colectiva. Castells desarrollará ampliamente este extremo y puntualizará que dicha auto-organización tiene un alcance limitado: para garantizar el éxito de las propuestas emanadas desde los movimientos sociales urbanos se hará preciso implicar a agentes con capacidad de decisión operativa en la gestión de la ciudad.

Lefebvre, de hecho, condicionaba también, de alguna forma, la eficacia de dichas propuestas a una serie de factores deseables. Si la "autogestión generalizada" es para Lefebvre el horizonte idóneo en el que la 
ciudad logrará ser producida de manera que cubra las necesidades de quienes la habitan, al mismo tiempo señala que solo los procesos políticos colectivos podrán concretar efectivamente esas propuestas; asimismo, para que desde la sociedad pueda asumirse con éxito esta función de emprendimiento cívico, habrá de dotarse no solo de las herramientas que se obtengan de una acción política continuada, sino servirse también del conocimiento científico sobre la ciudad: "Recíprocamente, la ciencia de la ciudad aporta a esta perspectiva un fundamento teórico y práctico, una base positiva" (ob. cit., p. 136). Lefebvre abre así a la ciencia de la ciudad la posibilidad de ser una herramienta de las iniciativas emprendidas desde la sociedad y no únicamente — como con preocupación expresó en otros momentos de su análisis- un instrumento de la acción coactiva de las élites.

Para sobrepasar los márgenes impuestos en el conocimiento sobre la ciudad, el científico ha de estudiar como elemento esencial de la realidad urbana la utilización del espacio por parte de los individuos - la ciencia de la ciudad sería, a diferencia de otras ciencias sociales, una "ciencia del uso" (Lefebvre, 2013, p. 400)—, e incorporar la crítica al análisis de la ciudad: "La ciencia del espacio (espacio-análisis) situaría en primer plano el uso del espacio, sus propiedades cualitativas. En este conocimiento, el momento crítico (crítica del saber establecido) resulta esencial: el conocimiento del espacio implica la crítica del espacio" (Lefebvre, 1983, p. 434). Y es que la ciudad no es tan solo fruto de la actividad tecnocrática de los expertos, científicos y urbanistas, y de las entidades ante las que aquéllos responden. La ciudad, a su vez, es producto de una "práctica urbana" imbricada en la vida cotidiana "que no se reduce ni a las ideologías e instituciones globales relativas al espacio y a su organización, ni a las actividades particulares llamadas "urbanísticas' que sirven de medios para fines frecuentemente desconocidos" (ob. cit., p. 94). La práctica vivida de la ciudad, resultante de habitarla, no está sujeta a la dinámica de los planificadores ni de los inversores: la práctica vivida de la ciudad, mediante la asiduidad del uso, re-define la ciudad e incide en ella de forma fundamental.

La ciencia puede ocupar en las relaciones de producción de lo urbano distintas posiciones. La labor del científico - y del filósofo- no estaría a salvo de diluirse en ellas, como les ocurre a los urbanistas (vid. infra): las disciplinas científicas "en el marco industrial solo podrán oscilar entre el papel de servidores de los intereses (privados o públicos) y el discurso" (ob. cit. p. 147). Solo existirá una ciencia de la ciudad si consigue salir del marco generado por el poder:

La ciencia del fenómeno urbano, ¿debería responder a exigencias pragmáticas, a inmediatos mandatos? Planificadores, programadores y utilizadores airean sus recetas respectivas. ¿Con qué fin? Para hacer que la gente sea feliz. Para ordenarla (sic) que sea feliz. Extraño concepto de la felicidad. La ciencia del fenómeno urbano no puede acceder a tales órdenes sin correr el riesgo de asumir una serie de obligaciones de origen externo: las provenientes de la ideología o del poder. Dicha ciencia se constituye lentamente, utilizando tanto hipótesis teóricas y experiencias prácticas como conceptos ya superados. No puede ignorar la imaginación, es decir, la utopía. A medida que va avanzando, debe tener en cuenta situaciones diversas" (Lefebvre, 1983, p. 146).

Las ciencias de lo urbano han de revisar sus propias categorías y conceptos (señala Lefebvre que la sociología está particularmente obli- 
gada a ello) y ser conscientes de la dimensión política del proceso de producción de la ciudad; por ello Lefebvre aboga por que se incorpore dicha dimensión en el análisis del fenómeno urbano. Así, la "ciencia de la realidad política (urbana)” puede generar una propia estrategia dual, "sin que se produzca separación, la estrategia se desdobla en estrategia del conocimiento y estrategia política" (ob. cit., p. 146). En la confrontación existente entre las estrategias sobre lo urbano (y en lo urbano), el desarrollo de una ciencia crítica conseguiría que la problemática de la ciudad se convirtiera finalmente en problemática política. Se abriría así también, por tanto, a ser útil a la sociedad urbana.

Las estrategias llevadas a cabo por las instituciones públicas y las empresas privadas pueden estar revestidas de la autoridad tecnocrática de los urbanistas. Estos realizan propuestas en función de una racionalidad supuestamente neutral, mediante la que inciden en un espacio que se considera desprovisto hasta entonces de forma o de contenido y que su intervención profesional habrá de conformar de forma técnica e imparcial. Pero considerar el espacio como un espacio en sí, sin apreciar las relaciones sociales inherentes a la producción del espacio, supone caer en una "trampa", en tanto que ello impide conocer las contradicciones implicadas en la misma (Lefebvre, 2013, p. 145). De esta forma, los especialistas no suelen tener en cuenta que su propio desempeño forma parte de este proceso dirigido por las élites, en el que relaciones de producción ya se han proyectado previamente sobre el espacio urbano. Es lo que Lefebvre llama la "ilusión urbanista", con la que la presunta legitimidad de los expertos queda en entredicho: "Los urbanistas parecen ignorar o desconocer que ellos mismos forman parte de las relaciones de producción que acatan las órdenes. Creen dominar el espacio y únicamente ejecutan." (Lefebvre, 1983, p. 159).

Lefebvre, por tanto, señala la adopción del conocimiento de la nueva "ciencia de la ciudad" por parte de los promotores sociales y políticos de nuevos modelos urbanos como otro de los factores que pueden dotar a las políticas institucionales de una mejor adecuación al modelo de ciudad habitable (Lefebvre, 1983, p. 146). El propio urbanismo como disciplina específica, desde rupturas paradigmáticas diversas (Gottdiener y Hutchison, 2011, pp. 330-331; pp. 346-347; Gehl y Gemzøe, 2002, pp. 14-19) propone actualmente la adopción de medidas para la restricción del uso del automóvil —una de las recomendaciones explícitas que Lefebvre realiza en materia de movilidad (vid. infra.) - y la promoción del ciclismo urbano. En dicho sentido, podría afirmarse que la implantación del carril-bici en Sevilla no solo se basa en criterios científicos y técnicos no tan alejados a los aspectos señalados por Lefebvre a la hora de caracterizar su concepto de "ciencia de la ciudad" sino que responde a modelos urbanos que incorporan los principios de habitabilidad y sostenibilidad propuestos por "las ciencias de la ciudad" desde nuevos paradigmas hoy existentes (cuyos antecedentes podemos encontrar, precisamente, en Lefebvre y en otros autores por él influidos) y ya asumidos como preeminentes en foros internacionales, en amplios sectores académicos y en el tercer sector.

Hay otro elemento en la obra de Lefebvre cuya aplicación aquí resulta interesante: la prospección de nuevas necesidades. Frente a un modelo de intervención de las administraciones públicas que atienda a demandas identificadas desde una lógica mercantilista (estudios de mercado, por ejemplo), el autor propone una planificación social que sustituya a la económica. Este nuevo modelo de planificación soslayará las demandas expresas por otras de carácter colectivo aún por descubrir: 
Orientar el crecimiento hacia el desarrollo, por tanto hacia la sociedad urbana, quiere decir ante todo: prospeccionar las necesidades nuevas, sabiendo que semejantes necesidades se descubren a lo largo de su aparición y se revelan a lo largo de la prospección. No preexisten como objetos. No figuran en lo «real» que los estudios de mercados y de motivaciones (individuales) describen. Ello supone por consiguiente substituir la planificación económica por una planificación social, cuya teoría apenas está elaborada. Las necesidades sociales conducen a la producción de nuevos «bienes» que no son este u otro objeto sino objetos sociales en el espacio y en el tiempo (Lefebvre, 1978, p. 147).

Ante la propuesta lefebvriana de guiarse por la prospección de "necesidades nuevas", hemos de señalar, en lo tocante al caso de estudio aquí elegido, que la apuesta del Ayuntamiento de Sevilla por el fomento de la bicicleta como modo de transporte urbano se caracterizó por dicho principio: la oferta de infraestructuras y dotaciones ciclistas no obedeció a lógicas de demanda individual expresa sino a la respuesta de una reivindicación realizada desde la autogestión (Lefebvre, 1978, p. 136), como fue el caso de las campañas a favor del carril-bici en la capital andaluza durante los años noventa (A Contramano, 2008, p. 4; Malpica, 2020, p. 157) desde posiciones de "discriminación vial": el ciclismo urbano en la Sevilla de aquella época era una forma de transporte desposeída - minoritaria, desregulada y desatendida, a menudo estereotipada y ridiculizada, en ocasiones arriesgada- cuya situación relegada favorecía el emprendimiento crítico hacia una resignificación del tráfico y del espacio urbano, en la línea de lo señalado por Lefebvre al hablar del protagonismo que se detenta desde posiciones de carencia, frustración y privación en el proceso de reapropiación de la ciudad (vid. supra).

Es más: en consonancia con el concepto de "planificación social" tal y como lo define Lefebvre, el estudio de la demanda del carril-bici sevillano se trataría por tanto de un proceso de prospección de nuevas necesidades que se construyeron en un proceso colectivo y que no atendió a las lógicas mercantilistas de una demanda "real" basada en la cuantificación del mercado formado por los consumidores ciclistas que por entonces existían. Dicho de otro modo, la construcción del carrilbici en Sevilla atendió a la demanda de cuantos ciclistas habría, no de cuantos ciclistas habia. La noción de una infraestructura cuya implantación debería atender las necesidades no solo de los ciclistas existentes, sino de los potenciales, estuvo presente en el planteamiento de la misma (Marqués, Hernández, Calvo y García, 2015, p. 34), concebida como una infraestructura "para todo el mundo" (ob. cit. p. 42). De hecho, las más extendidas críticas que recibió la iniciativa municipal - enarboladas en un ya tristemente famoso artículo de opinión que el tiempo se encargó de desmentir - consistían precisamente en tildar al carril-bici de "muy inútil" esgrimiendo como argumento el escaso número de usuarios de la bicicleta existente por entonces en Sevilla. Si concluimos que el caso del carril-bici sevillano cumple el requisito lefebvriano de que la necesidad surja durante el propio proceso de prospección (esto es, que la prospección no se limite a detectar la necesidad, sino que contribuya a crearla) es porque atendió no solo a los ciclistas, sino a los potenciales ciclistas (y no solo a aquellos que, en algunas de las encuestas que se realizaron, respondieran que utilizarían la bicicleta si dispusieran de una red de carriles-bici, sino incluso también a quienes por entonces aún no supieran que con la disponibili- 
dad de dicha infraestructura se animarían a convertirse en ciclistas). Como nos disponemos a analizar, en el proceso de implementación de infraestructuras ciclistas en Sevilla, este no será este el único rasgo propio coincidente con los requisitos lefebvrianos para un urbanismo que garantice el derecho a la ciudad.

\section{La movilidad urbana en la teoría de Lefebvre}

Lefebvre no es profuso en su obra a la hora de analizar el transporte en el espacio urbano (más bien lo emplea, y solo a veces, como ejemplo en una u otra argumentación). A través de algunas de estas alusiones (particularmente en Lefebvre, 1978), sabemos que el autor considera que el transporte no puede analizarse separadamente del sistema urbano: ambos son aspectos del problema general del espacio. Como el espacio social, el sistema de transporte también está producido en primera instancia por las élites, está caracterizado del mismo modo por la segregación, y se ve sometido igualmente a los fines de funcionalidad, productividad y mercantilización. El automóvil, por ejemplo, aparece señalado entre los distintos sistemas "de fines" que aparecen sobre la base económica del tejido urbano (cfr. Lefebvre, 1978, p. 26). Las políticas, normas, infraestructuras y dotaciones relativas al transporte y al tráfico habrán de interpretarse por tanto como estrategias coadyuvantes para la producción del espacio por parte del Estado y el mercado — si bien no sería inadecuado inferir al mismo tiempo que el uso del transporte por parte de los habitantes de la ciudad supone una oportunidad de reapropiación de la movilidad espacial, y por tanto del espacio.

Más allá de estas consideraciones sobre el transporte en general, es el automóvil el modo de transporte al que Lefebvre alude una y otra vez como producto de las estrategias del poder, contrapuestas a la ciudad de la sociedad urbana. Lefebvre responsabiliza al cientifismo de la Administración Pública de primar en sus políticas y planeamientos un racionalismo operativo que promueve un uso masivo y nocivo del automóvil, olvidando así el factor humano (ob. cit., pp. 41-42). También denuncia "el círculo mágico del asfalto", en expresión de Goodman: la espiral que se produce cuando, en casos como el de los Estados Unidos, los impuestos recaudados por las ventas de gasolina se invierten en la construcción de carreteras y autovías urbanas e interurbanas, lo que a su vez favorece los intereses de las compañías petroleras y a los fabricantes de automóviles, hecho que promueve un mayor uso de vehículos de motor y una mayor recaudación de impuestos en la venta de combustible, que se destinarán reiteradamente a nuevas obras públicas... De esta forma, "virtualmente, los coches y las carreteras ocupan el espacio entero" (Lefebvre, 2013, p. 406). Este tipo de procesos suponen una amenaza para una ciudad verdaderamente habitable.

La invasión de automóviles y la presión de su industria, es decir, del lobby del auto, han convertido el coche en un objeto piloto, al aparcamiento en una obsesión, a la circulación en un objetivo prioritario, y a todos ellos en su conjunto en destructores de toda la vida social y urbana. Muy pronto será necesario limitar, no sin dificultades y estragos, los derechos y poderes del auto (Lefebvre, 1983, pp. 24-25).

Lefebvre, por todo ello, terminará alertando de la necesidad de limitar la preeminencia del coche (no sin el previsible esfuerzo que ello 
implicará) y abogará por la sustitución mediante el fomento de otros medios de transporte. A pesar de que él mismo tilde el siguiente ejemplo de "un poco simple y trivial", sus palabras son inequívocas en lo que respecta a la necesidad de limitar el uso del automóvil e introducir en su lugar nuevos medios de transporte:

Aquí es factible concebir una variable estratégica; limitar la importancia de la industria del automóvil en la economía de un país y el lugar en la vida cotidiana, en la circulación, en los medios de transporte del objeto «auto». Substituir el automóvil por otras técnicas, otros objetos, otros medios de transporte (por ejemplo, públicos) (Lefebvre, 1978, p. 151)

Pero más allá de sus afirmaciones sobre este u otro modo de transporte, el análisis de la movilidad en la obra de Lefebvre reside, al estudiar la ciudad, en su interés por la relación del tiempo y el espacio, factores ambos concurrentes en la realización de un trayecto. El desplazamiento es espacio consumido (Lefebvre, 2013, p. 382); los transportes intentan reducir el tiempo al empleo apremiante del espacio (ob. cit., p. 424). En sus últimas obras, Lefebvre presta particular atención al análisis del tiempo y el espacio tomados conjuntamente (apartándose expresamente del estudio de tiempo y espacio por separado que tradicionalmente se venía realizando), aunados de forma novedosa en el ritmo de lo urbano. Con el ritmo-análisis (Lefebvre, 2006, pp. 229-231) Lefebvre propone abordar el estudio de la ciudad desde la identificación de los ritmos que esta alberga, sobre todo aquéllos generados de forma espontánea por sus habitantes y por el uso de la ciudad que estos realizan. De hecho, en su descripción del ritmo de la ciudad, los transportes (los automóviles y los viandantes, en particular) son un elemento particularmente frecuente. Los ritmos del transporte, como todos los ritmos, son relativos: no pueden ser medidos como se mide la velocidad de un vehículo en su trayectoria desde un punto de salida a una meta tomando una determinada unidad de medida: "un ritmo es rápido o lento solo en relación con otros ritmos con los que esté asociado dentro de una mayor o menor unidad" (ob. cit., p. 230).

Los ritmos, en aparente desorden, crean un orden que da cabida a las manifestaciones de la vida urbana. Para realizar un análisis del ritmo de la ciudad es importante percibir los sonidos que esta genera. También han de observarse sus flujos, sus movimientos, todos ellos vinculados a un espacio sin por ello dejar de ser un tempo. La observación del ritmo de la ciudad tiene también una dimensión micro. El ritmo del propio cuerpo debe estar presente en el análisis de los ritmos de la ciudad.

Es preciso aclarar que la utilización que hacemos aquí del término micro, en tanto que se refiere al espacio contiguo al cuerpo del ser humano y a la relación entre este y aquél, no es del todo coincidente con el uso de dicho término por Lefebvre. Cuando alude en su obra expresamente a lo micro, Lefebvre lo ejemplifica con ámbitos algo más amplios, como el vecindario (Lefebvre, 2013, p. 419) o la escala arquitectónica (ob. cit., p. 121). Lefebvre sí hace referencia al entorno cercano del ser humano al tratar fenómenos como la práctica y el uso que este realiza del espacio, o la relación de su cuerpo con el espacio; de hecho, le interesa subrayar en ellos la intervención inmediata del individuo sobre su ámbito más próximo, y podrá entonces ilustrarlos con elementos específicos como la calle, la travesía o la acera (Lefebvre, 1983, p. 184), las superficies de un supermercado (Lefebvre, 2013, p. 441) o en 
el ámbito aún más íntimo que circunda el propio cuerpo del individuo. La atención a la inmediatez entre cuerpo y espacio no aparecía —al menos no de forma tan rotundamente expresa- en los inicios del "periodo urbano" de la obra de Lefebvre. Con el desarrollo, en sus últimas obras, del ritmo-análisis, acentúa su interés por el ámbito espacial más cercano al individuo, prestando una atención al cuerpo humano como generador del espacio. El uso del espacio cobra ahora una dimensión más corpórea -incluso sensitiva- que nos permite centrarnos en la interacción del individuo con su espacio circundante inmediato y proyectar el alcance de dicha interacción micro en la producción del espacio urbano en su conjunto.

El espacio entero (social) procede del cuerpo, aunque sufra tales metamorfosis que lo hagan olvidar, aunque se separe de él hasta matarlo. La génesis del orden lejano no puede exponerse sino a partir del orden más cercano a nosotros, el orden del cuerpo. En el cuerpo mismo, considerado espacialmente, las sucesivas capas de sentidos [...] prefiguran las capas del espacio social y sus conexiones [...]. El análisis de los ritmos debe servir a la necesaria inevitable restitución del cuerpo total. De ahí la importancia del ritmo-análisis (Lefebvre, 2013, pp. 434-435).

Ello supone una gran aplicabilidad a la hora de analizar algunas de las características del ciclismo urbano. El ritmo-análisis nos permite incorporar el estudio de aspectos poco habituales en el análisis sociológico: los ritmos de la bicicleta (su rapidez, su agilidad y su maniobrabilidad, obviamente; pero también el reiterado pedaleo, la secuencia de frenados, sus sonidos: el característico timbre, su silencio en comparación con la práctica totalidad del resto de vehículos, o incluso la cadencia de la cadena sobre el piñón); aspectos asociados a la vivencia del ritmo ciclista (la inmediatez del entorno, la facilidad de la parada, la visibilidad — ver desde la bicicleta y ser visto en ella-, la independencia, la sensación térmica en la piel: el viento en el rostro, inherente a la sensación de ir en bicicleta); la interacción del ritmo ciclista con la de otros agentes móviles (el ritmo del automóvil, el ritmo de la motocicleta, el ritmo del transporte público, el ritmo de los patinadores, el ritmo del peatón: sus sonidos, sus velocidades, sus movimientos); los ciclos temporales (el uso de la bicicleta a diferentes horas del día, en diferentes días de la semana, en las diferentes estaciones del año). Analizar aspectos como los recién enumerados supone una ortodoxa aplicación de las indicaciones metodológicas especificadas por Lefebvre al proponer dicha herramienta analítica. De hecho, encontramos paralelismos entre ella y el aspecto corporal de las disposiciones sociales según Bourdieu (1998, p. 215). Si en la matriz bourdieuana el tipo de relación con el propio cuerpo, inherente a cada habitus, facilita el acceso a ciertas prácticas de actividad física que satisfagan necesidades distintivas del mismo, el proceso corporal que describe Lefebvre respecto a la incorporación del espacio a través del uso y la consecuente producción espacial que ello genera podría asimilarse, en líneas generales, a la relación entre habitus y cuerpo establecida por Bourdieu y a la dimensión estructurada y estructurante de aquél.

La acción del cuerpo en y sobre el espacio inmediato supone un ejercicio de apropiación, y no solo física. el individuo toma una posición y no solo ocupa un espacio, sino que lo incorpora: "El individuo sitúa su cuerpo en su propio espacio y aprehende el espacio alrededor del cuerpo" (Lefebvre, 2013, p. 256). La experiencia espacial, en tanto 
que "vivida" y corporal, se encarna en el individuo: en su conciencia y en su conocimiento (ob. cit., p. 180). Ello supone reconocer en el cuerpo una capacidad de agencia sobre el espacio y en la producción del mismo. Hemos de considerar, por tanto, que la acción entre cuerpo y espacio es de doble sentido y que la incidencia entre uno y otro es recíproca a través del uso - en palabras de Kidder (2009, p. 325), "el espacio es siempre una parte de la práctica”- Desde esta aportación de Lefebvre, podemos inferir que el individuo, al situarse en el espacio, al observarlo e interpretarlo, y posteriormente al tomar decisiones en y sobre el espacio, llevándolas luego a cabo, no hace sino actuar desde el espacio aprehendido anteriormente. Podrá por tanto (también desde el sillín de una bicicleta) desarrollar destrezas cinéticas y ejecutar estrategias espaciales desde su experiencia creciente con el entorno, en un ejercicio que en líneas generales es común con quienes compartan su misma práctica espacial y de movilidad. De esta forma podrá incidir en el espacio en mayor medida, resignificándolo, y aprehenderá e incorporará, mediante esa vivencia, el conocimiento del espacio recién producido por él.

Como el concepto bourdieuano de habitus (cfr. Bourdieu, 1988, p. 54; 2008, p. 86), la incorporación del espacio en Lefebvre ha de ser vista como disposición estructurada y estructurante con una dimensión de carácter claramente corporal (aunque no únicamente corporal, en tanto que también se encarna en su conciencia y en su conocimiento), adquirida y ejecutada desde y para la práctica, compartida con quienes forman parte de una misma "posición social" y definida por los límites emanados por las condiciones de producción (espacial). Si afirmamos, con Bourdieu, que el tipo de relación con el propio cuerpo, inherente a cada habitus, facilita el acceso a determinados medios de transporte y a ciertas prácticas de actividad física que satisfagan necesidades distintivas del mismo, el proceso corporal que describía Lefebvre sobre la incorporación del espacio a través del uso y la consecuente producción espacial que ello genera podría asimilarse, en líneas generales, a la relación entre habitus y cuerpo establecida por Bourdieu y a la dimensión estructurada y estructurante de aquél. La aportación sustancial de Lefebvre sería, en este sentido, la consideración del aspecto espacial en dichas disposiciones.

Basándose en el análisis de Lefrebvre y aplicándolo a la movilidad en bicicleta, Kidder (2009) señala que el espacio del ciclista se convierte en algo explícitamente cultural, en el cual podemos entender la importancia del emplazamiento de la acción: a través del análisis etnográfico de la movilidad de los bicimensajeros se propone llenar cierto vacío teórico "emplazando debidamente las prácticas culturalmente significativas [...] dentro del entorno en el que ocurre" (p. 324), en tanto que, según el mismo autor, "el espacio se torna explícitamente cultural -en el cual podamos entender el significado de la acción emplazada" (ob. cit. p. 322). De esta forma, Kidder considera la práctica ciclista per se un elemento transformador del espacio urbano y una forma inmediata de reapropiación del mismo mediante el uso. De forma similar, Augé (2009, p. 60, 65, 75) reitera en diversas ocasiones la capacidad de transformación y de reapropiación de la ciudad inherente a la mera utilización de una bicicleta.

Por tanto, a la hora de hablar de cómo la bicicleta transforma el espacio urbano, y si tomamos en consideración el concepto de reapropiación de la ciudad en toda la amplitud, no hemos de atender únicamente a los procesos participativos o a las reivindicaciones colectivas 
impulsadas por los movimientos sociales (entre ellos, el ciclista), sino también a este modo de resignificación espacial vinculada a la corporeidad, a la inmediatez, al ritmo, al tempo y a la agencia en lo micro, lo que en el caso del ciclismo urbano supone una dialéctica de oposición frontal al modelo mercantalista de movilidad. Así, al intentar caracterizar la movilidad en bicicleta es común encontrar referencias al carácter ágil, rápido y maniobrable de dicho vehículo, así como a la eficacia y la versatilidad como atributos específicos de la conducción ciclista. Las implicaciones de estas características del uso de la bicicleta, de su relación con el espacio urbano y de su interacción con los elementos de dicho espacio - distribución de la superficie, mobiliario urbano, otros agentes móviles, tráfico, normas- suponen aspectos fundamentales en el análisis del ciclismo urbano, y entroncan con el análisis de Lefebvre sobre la producción social del espacio a través del uso del entorno y de las resignificaciones que con dicho uso se realizan. Es posible entender este tipo de reacciones prácticas y discursivas en el contexto de lo que Lefebvre caracterizó como fórmulas contrapuestas de producción del espacio, donde la ciudad habitada resignifica a la ciudad planificada a través del uso del espacio y de la apropiación del mismo.

El particular estilo de movilidad ciclista (en especial, la desobediencia a las normas que en mayor o menor grado suele caracterizarlo) puede enmarcarse en el concepto de reapropiación de Lefebvre y su reivindicación del derecho a la ciudad: las infracciones realizadas desde una lógica ciclista pueden interpretarse como elementos de la dialéctica entre la ciudad vivida y la ciudad concebida. Desde este punto de vista, las normas de tráfico habrían de asimilarse como estrategias del proceso de funcionalización, segregación y mercantilización descrito en la obra de dicho autor:

Este orden del espacio genera lo que Lefebvre denomina un supuesto consensus, que estaría tácitamente asumido por todos los usuarios, basado en las clásicas pautas de urbanidad, que coincidirían a generar una convivencia segura y apacible, evitando molestias y ofensas hacia los demás. Sin embargo, basándose en «una sobreabundancia de reglamentaciones draconianas», dicho consensus no hace sino limitar la presencia, la acción y el discurso de los actores. Esto es, bloquea la posibilidad de plantear cualquier orden espacial alternativo o incluso introducir modificaciones en el ya existente (Ion Martínez Lorea, en Lefebvre, 2013, p. 22).

El ciclismo urbano como práctica heterodoxa ha conseguido en ocasiones incorporar y generalizar, al menos en alguna medida, elementos de este "orden espacial alternativo" aludido por Martínez Lorea como prologuista de la obra de Lefebvre. De hecho, muchas de las infracciones propias de los ciclistas inspiran nuevas normas (por ejemplo, muchas ciudades han implantado la conducción de bicicletas en doble dirección en calles que son de un solo sentido para los automóviles; en el caso de Sevilla, esta medida llegó a plantearse, pero fue vetada por sectores institucionales poco favorables al ciclismo urbano). En otros casos, algunos de los efectos de la desobediencia ciclista se valoran en determinados ámbitos como positivos y recomendables, en tanto que contribuyen a lograr objetivos de interés general (pacificación del tráfico, descongestión de la vía pública, etc.). En muchas otras ocasiones, sin embargo, plantean situaciones no solventadas y que, generalmente, se gestionan a través de mecanismos informales de control social: muchas infracciones de peatones, de ciclistas y de conductores 
de vehículos motorizados constituyen una disputa por el espacio entre estas tres formas de locomoción y generan frentes de conflicto pendientes de resolución. Podemos considerar al respecto que existe una negociación en curso donde cada grupo de interés mide sus fuerzas, y ejerce o cede parte de los derechos que considera legítimos para sí en función del balance de cada coyuntura (coyunturas analizables tanto en el marco legal, económico e institucional como en el estrictamente espacial y, dentro de este último, puede estudiarse tanto la dialéctica micro-espacial como la comparación general de flujos móviles o de la superficie urbana dedicada a uno u otro tipo de movilidad). Los resultados que progresivamente se alcancen, en uno u otro sentido, conformarán espacios urbanos diferentes.

\section{El carril-bici de Sevilla como producción del espacio: ¿infraestructura coercitiva o fomento del derecho a la ciudad?}

Lefebvre muestra repetidas veces su desconfianza ante la posibilidad de que las instituciones públicas puedan tutelar una iniciativa que favorezca realmente a la sociedad urbana, dado que estas iniciativas acaban siendo engullidas por la dinámica de control del Estado y ejecutan un modelo de producción de la ciudad contrario a la habitabilidad del espacio urbano. ¿Puede aun así una intervención urbanística favorecer la consecución de un modelo de ciudad más habitable?

Tomando como caso la implementación del carril-bici de Sevilla y contrastándolo con la obra de Lefebvre, la respuesta debería ser afirmativa. De hecho, Lefebvre concede a las iniciativas de reforma urbana un cierto valor de resistencia frente a la ciudad "coactiva" emanada desde el Estado, matizando así su pesimista desconfianza hacia la acción de las administraciones sobre el espacio urbano. A la hora de especificar las características de una intervención urbanística que pueda ser considerada "revolucionaria", señala la conveniencia de que los promotores y ejecutores de dichas reformas tengan en cuenta las conclusiones que desde los paradigmas de las nuevas disciplinas científicas de la ciudad se realicen y que establezcan alianzas con entidades representativas de los intereses de la población y con la población misma:

Cada proyecto de reforma urbana pone en entredicho las estructuras, las de la sociedad existente, las de las relaciones inmediatas (individuales) y cotidianas, pero también las que se pretende imponer por vía coactiva e institucional a lo que queda de realidad urbana. La estrategia de renovación urbana, reformista en sí, se torna "forzosamente" revolucionaria, no por la fuerza de las cosas sino porque va en contra (sic) las cosas establecidas. La estrategia urbana fundada en la ciencia de la ciudad tiene necesidad de apoyo social y fuerzas políticas para operar. No actúa por sí sola (Lefebvre, 1978, p. 133).

La decisión del Ayuntamiento de Sevilla de implantar una red de carril-bici desplegada por toda la extensión del municipio constituye una intervención urbanística de la Administración Pública y, aun así, podría encuadrarse en esta consideración excepcional de Lefebvre sobre algunos proyectos de reforma urbana. Fue impulsada con mayor énfasis durante el equipo de gobierno municipal de coalición, formado por Partido Socialista Obrero Español e Izquierda Unida; sin embargo, el 
proceso de implantación del carril-bici se desarrolló bajo las competencias de la segunda de estas fuerzas políticas (Castillo y Sánchez, 2013, p. 1013; Calvo, 2013, p. 125), cuya presencia en las instituciones es menos frecuente que la de otros grandes partidos mayoritarios, y cuyo programa —en este caso, municipal- suele incluir políticas que divergen de los programas propios del bipartidismo; es, en este sentido, a los efectos del presente análisis, un partido político no convencional cuya acción de gobierno, al menos en el caso que nos ocupa, no es asimilable a las dinámicas institucionales hasta entonces habituales. Como elemento aún más decisivo la propuesta tenía un gran componente participativo: contaba no solo con el respaldo, sino con la colaboración del tejido asociativo de la ciudad, en particular con la asociación ciclista A Contramano. La propuesta de implantación de un sistema de carril-bici había partido, años antes, de los primeros procesos de presupuestos participativos realizados en la ciudad, en los que dicha iniciativa fue la más votada de entre todas las postuladas (Malpica, 2020; Marqués, 2011). La voluntad de que existiesen mecanismos de participación social en el proyecto de la actual red de carriles-bici se concretó también con la creación por parte del Ayuntamiento de la Comisión Cívica de la Bicicleta compuesta por "asociaciones de peatones y ciclistas, empresas del mundo de la bicicleta, técnicos municipales y, en general, cuantos actores se consideran relevantes para el desarrollo del Plan Director" (Marqués, 2011, p. 112), y con una función de interlocución y participación ciudadana en el proceso (cfr. Marqués et al., 2015, p. 36; Malpica, 2020, p. 159). El caso, por tanto, cumple el requisito que Lefebvre señala para poner en marcha una estrategia de reforma urbana, en virtud del cual las instituciones han de contar con "apoyo social y fuerzas políticas”. De ello se muestra convencido Marqués:

Con independencia de la opinión que merezcan las actuaciones reseñadas, es evidente que no han partido de cero, sino que han surgido de un caldo de cultivo previo. Es también evidente que no han sido fruto de la improvisación o de la casualidad, sino que han respondido a la existencia de una clara determinación política y a un plan coherente que ha contado en todo momento con el consenso de los usuarios, así como con la colaboración de las instituciones ciudadanas más interesadas en el fomento de la movilidad urbana en bicicleta (Marqués, 2011, p. 114).

Autores como Sanz (2008, p. 16) o Gaviria (2006, p. 5) abogan por garantizar la participación social en la definición de los planes de movilidad urbana y que desde los ámbitos representativos del ciclismo urbano se redoblen los esfuerzos de interlocución con técnicos, urbanistas y políticos. Torres Elizburu (2003, p. 109) observa como una carencia la ejecución de infraestructuras ciclistas sin conocer las preferencias y demandas del usuario. También Hanson y Young (2008, p. 394) señalan la importancia de los mecanismos de consulta a las asociaciones ciclistas y vecinales por parte del gobierno local. Sin embargo, en el proceso del caso sevillano, nos resistimos a reducir la interacción entre el asociacionismo y las instituciones municipales a mera "interlocución". Como se observa al analizar la evolución de la red promotora del ciclismo sevillano (Malpica, 2020), se constata una apreciable integración de los activistas en el equipo gestor de las actuaciones municipales, ejerciendo un notable grado de influencia en los espacios de toma de decisiones en aspectos como el diseño del carril-bici o la proyección internacional de sus resultados, entre otros muchos ejemplos de inter- 
vención y cooperación. Ello fue posible, más allá de la afinidad entre unos y otros agentes, por la trayectoria en los movimientos sociales y la legitimidad detentada por las personas que conformaron el grupo promotor, así como por la disposición de apertura y voluntad política desde ciertos sectores de las instituciones y los partidos políticos. Respecto a su vínculo con las prácticas ciclistas, es imprescindible considerar que los miembros de A Contramano son ciclistas urbanos, por lo que han incorporado a lo largo de su vida una serie de disposiciones, compartidas con el conjunto de usuarios de bicicletas e interiorizadas a través de la experiencia ciclista. En este aspecto es donde se puede articular la teoría de Bourdieu con la de Lefebvre, quien - recordemos - también analizó la apropiación del espacio a través de la incorporación de la propia situación espacial y la interacción con el entorno; ambos autores describen un proceso de encarnación de la experiencia a través de la práctica cuyas manifestaciones corporales, sin ser las únicas, resultan ser de carácter fundamental. La combinación de esta experiencia personal ciclista de los miembros de A Contramano con la de su trayectoria activista y su bagaje técnico y científico supuso una miscelánea de saberes desde la que difundieron la necesidad de satisfacer una demanda social y a contribuir desde su conocimiento especializado a concretar el proyecto con el que se respondía a la misma, detentando un gran capital simbólico hacia el resto del grupo de promotores.

La incorporación de la red de activistas pro-bicicleta sevillanos a los ámbitos de diseño, gestión y toma de decisiones facilitó la intervención de los miembros de las asociaciones en el ámbito de los "operadores” decisorios, lo que, tal como señala Castells (1986, p. 409; p. 444), supone una garantía para la consecución de los objetivos planteados por los movimientos sociales urbanos. Estos generan demandas desde una lógica del valor de uso que limitan la conformación de modelos de ciudad emanadas exclusivamente desde parámetros productivistas con lógicas de valor de cambio, y pugnan por una significación urbana diferente a la impuesta por la planificación urbanística institucional (Castells, 1986, pp. 431-432; 1988, p. 310). Pero Castells (1986, p. 409) también nos señalaba que los movimientos sociales resultan insuficientes por sí mismos para que sus reivindicaciones concretas puedan finalmente llevarse a la práctica, e indicaba la idoneidad de que desde el tejido asociativo se emprendieran mecanismos de cooperación con otros diversos agentes - partidos políticos, especialistas, etc. - con el fin de alcanzar sus fines. Hanson y Young (2008, p. 405) parecen mostrarse de acuerdo al afirmar que "la presión de los movimientos sociales probablemente fracase a no ser que operadores clave de la administración pública crean en la importancia del ciclismo en el sistema general de transporte". Ello es aplicable al caso del activismo pro-bicicleta sevillano: la naturaleza misma de la demanda ciudadana en pro de un carrilbici en Sevilla supuso una ruptura con el enfoque mercantilista del modelo de movilidad municipal de la época, cuya matriz prioritaria se focalizaba en el automóvil, y promovía otro concepto de ciudad. A Contramano estableció vínculos a lo largo del proceso con partidos políticos, con urbanistas, con consultores medioambientales, con la Universidad de Sevilla, etc. y colaboraba con el propio Ayuntamiento de la ciudad (dotando a la institución, a su vez, del elemento transformador del espacio urbano que la institución, por sí misma, resulta incapaz de implementar, tal y como hemos visto que afirma Lefebvre a lo largo de su obra). Asimismo, Castells (2001, p. 164) concibe los movimientos sociales de la Sociedad-Red como iniciativas autogestionadas conectadas 
no solo con otros movimientos sociales locales sino con iniciativas similares existentes en otras ciudades y países. Ante el proceso de sinergias entre el ámbito institucional, político y asociativo que ha caracterizado el caso de Sevilla, así como la retroalimentación que en dicho caso se desarrolló con alcance internacional (Marqués, 2011, p. 12; Malpica, 2020), concluyamos, con Castells, que sin dichas alianzas difícilmente hubiera podido lograrse el éxito alcanzado.

Otro factor digno de consideración es el hecho de que la reivindicación histórica de un carril-bici en la ciudad fuese promovida por quienes utilizaban un vehículo calificable - aun ahora, pero en mucha mayor medida entonces- como "desfavorecido" o "minoritario". El uso de la bicicleta en Sevilla previamente a la construcción del carril-bici, era marginal —en los dos sentidos de la palabra: era muy minoritario y se asociaba a estilos de vida críticos o a expresiones contraculturales. En este último sentido, la opción de la bicicleta suponía una suerte de apuesta personal frente a la prescripción mayoritaria: la carencia de dotaciones y políticas de apoyo, así como la escasa "aceptación" social e institucional, eran factores que se traducían en evidentes obstáculos para quienes decidieran elegir la bicicleta como alternativa de transporte. Respecto a todo ello, no podemos evitar aquí recordar la reflexión de Lefebvre sobre las minorías excluidas y sobre cómo estas suelen caracterizarse por una mayor preocupación y actividad sobre lo urbano, desempeñando una importante función de participación en la generación de espacios habitables y en la apropiación de la ciudad (Lefebvre, 1978, p. 119; 2013, p. 405).

En el caso aquí analizado, el proceso de apropiación por parte de los ciclistas ha atravesado diversos momentos. Comenzando por el más reciente, podemos distinguir en el éxito del carril-bici sevillano la culminación de un largo proceso de apropiación: tras la implantación del mismo, decenas de miles de ciclistas se apropian de la infraestructura que les es ofrecida desde las instituciones, en un grado que sorprende, por numeroso, incluso a los ciclistas urbanos "veteranos" (y que sorprende aún más, o así es de suponer, a quiénes habían augurado el fracaso de la "muy inútil" infraestructura). Nótese que de dicha infraestructura se apropia la ciudadanía de acuerdo con la finalidad con la que fue concebida por las instituciones, lo que supone un ejemplo opuesto al fracaso de muchas dotaciones ofertadas por los ayuntamientos a las que Rodríguez Díaz (2008, pp. 191-193) tipifica como "relaciones descompensadas", caracterizadas por el desajuste entre la oferta municipal y la necesidad de uso. La apropiación espacial de la infraestructura, además, es productora de espacio, en el sentido de que la funcionalidad del carril-bici y el uso que los ciclistas hacen de él son dos elementos que se retroalimentan: por una parte, la apropiación del carril-bici es consecuencia de la funcionalidad del mismo - la infraestructura ofrece condiciones de seguridad, conectividad y comodidad que propician un aumento de los ciclistas urbanos- y es, al mismo tiempo, garantía de su funcionalidad -o "defensa del territorio", si se quiere- al evitar que pueda ser ocupado con otros usos (en ciudades con poco flujo ciclista, los carriles-bici terminan siendo ocupados por los viandantes o como espacio de aparcamiento de automóviles, haciéndolo impracticables para el transporte en bicicleta). En este sentido, el carril-bici per se no garantiza la producción del espacio en todo el sentido del concepto: es el uso del carril-bici, en tanto que mantiene las condiciones para su funcionalidad, el que sigue produciendo el espacio del carril-bici. 
Pero mucho antes de que el proceso desembocara en la construcción de la red de vías ciclistas y en el consiguiente auge del ciclismo urbano, tuvo lugar lo que podemos considerar una fase inicial de apropiación: la generación colectiva de la demanda de un carril-bici para la ciudad de Sevilla —expresada en el lema Carril-bici, iya! que se leía en las míticas placas de plástico que la por entonces reducida comunidad ciclista sevillana colgaba de sus bicicletas y que se coreaba en las manifestaciones reivindicativas que A Contramano convocaba- y que en efecto supone un proceso lefebvriano de apropiación colectiva mediante la auto-organización. A lo largo del tiempo, las movilizaciones ciclistas se mantuvieron con variable intensidad y acudiendo a nuevos formatos: en los años previos a la construcción de la actual red de carriles-bici - junto a las marchas ciclistas "clásicas", que se mantenían desde décadas atrás- apareció también un nuevo modelo de reivindicación de difusión internacional: la "Masa crítica" o "Bici crítica" (Horton, 2006, p. 55; Horton, Rosen y Cox, 2007, p. 145; Weikart, 2006, pp. 93-116) iniciativa autogestionada, convocada informalmente, y reproducida en Sevilla por un grupo de ciclistas (entre ellos, miembros y simpatizantes de A Contramano), claro ejemplo del modelo de movilización global resultante de la coordinación en red por parte de los movimientos sociales señalada por Castells (2001).

Por tanto, las movilizaciones ciclistas existentes en Sevilla desde finales de los años ochenta hasta la actualidad, convocadas en diversos formatos en consonancia con los distintos tiempos, han supuesto sin lugar a dudas una práctica política de apropiación de la ciudad. Sin embargo, y como una fase incluso anterior a la fase de la movilización asociativa, hemos de tener también en cuenta la apropiación del espacio urbano que - mientras tanto y aun antes- hicieron día tras días los usuarios de la bicicleta como alternativa de transporte, quienes en un inicio pudieron ser unos pocos centenares - tal vez, como mucho, algunos millares-. Como hemos señalado ya desde Lefebvre, hemos de considerar la conducción ciclista espontánea como una apropiación corpórea del espacio y un proceso de producción espacial urbana a través del uso, llevado a cabo a través del ejercicio individual de elegir la bicicleta como medio de transporte por las calles de una ciudad que les desatendía: un uso habitual del espacio que se intentaba abrir paso contra el modelo de urbe producido desde las lógicas funcionalistas y productivistas. De hecho, aquella apropiación política no hubiera tenido lugar sin esta otra apropiación vivida.

La fusión de ambas formas de apropiación — la inherente al uso y la autogestionada - podría condensarse en las ya referidas placas de plástico con el lema "Carril bici, ;ya!", punto de encuentro entre la reivindicación organizada y la movilidad de uso: mientras que la asociación $A$ Contramano generó el lema y produjo las placas de plástico, fueron los ciclistas urbanos de la época quienes las incorporaron, ciñéndolas a sus bicicletas, y distribuyeron el mensaje por la ciudad a través de sus propios desplazamientos, mediante los cuales, paralelamente, producían un espacio urbano alternativo mediante su propia movilidad. La consecución de una red de carriles-bici a principios del siglo xxi condensa las muy diversas formas de apropiación espacial de la ciudad mantenidas a lo largo del tiempo y las expande al ponerlas al alcance de toda la población.

Rodríguez Díaz (2008, p. 39), estudiando las dotaciones deportivas de la ciudad de Sevilla, se hace eco de la capacidad organizativa de los usuarios como factor de influencia en la decisión política de destinar 
un espacio a la práctica de un deporte o ejercicio físico específico, y ejemplifica este proceso con algunos casos entre los que se encuentran los carriles-bici deportivos. También, aplicando las reflexiones de Lefebvre, estudia diferentes modelos de apropiación de espacios urbanos para fines deportivos (ob. cit., pp. 24-25; pp. 185 y ss.), algunos de los cuales parten de procesos espontáneos de apropiación que van institucionalizándose en fases posteriores. Si bien el carril-bici sevillano consiste en una red de vías ciclistas destinadas fundamentalmente al transporte y no al uso deportivo, sus conclusiones son claramente aplicables a nuestra investigación.

Vinculado al derecho a la ciudad, el derecho a la naturaleza constituye una reivindicación adicional de Lefebvre para la vida urbana (1978, pp. 137-138; vid. tb. Lefebvre, 2013, p. 90). La naturaleza — nos dice el autor - está presente en el ámbito urbano, bien deslizándose por las estrechas grietas que el espacio urbanizado apenas le deja libres, o bien a través de espacios que la representan, o la asemejan, pero en los que, replicando el juego de palabras que realiza el propio autor, la naturaleza ha sido despojada de su naturalidad, puesto que están destinados solo al ocio, segregados del resto de las actividades urbanas: el espacio "natural" urbano es así un lugar separado de esparcimiento, un retiro, un gueto. Los espacios naturales urbanos, asimismo, se organizan institucionalmente, se mercantilizan y se segregan. Ante el análisis de Lefebvre sobre el espacio natural urbano, podemos vincular en cierto grado el "derecho a la naturaleza" a la intervención en el espacio urbano para promover el ciclismo.

En este sentido, Horton (2006, pp. 44-46) señala la tradicional connotación de la bicicleta como vínculo con "el mundo natural", y otros muchos autores desarrollan las ventajas medioambientales del ciclismo urbano (entre otros, Gaviria, 2006, p. 5; Hanson y Young, 2008, pp. 388-389 y p. 404; Marqués et al., 2015, p. 31). Algunos indicadores y medidas de los efectos medioambientales del carril-bici ofrecen su equivalencia en ahorro de combustible y reducción de los gases efecto invernadero emitidos (Marqués et al., 2015, p. 40), expresan el número equivalente de árboles plantados o el porcentaje de ahorro de consumo energético doméstico (Ayuntamiento de Sevilla, 2010, pp. 19-20). La red de carriles-bici de Sevilla es una infraestructura verde - no solo en lo referente al color del carril, sino en tanto que mejora el medio ambiente urbano, pacifica el tráfico motorizado y contribuye a una ciudad menos contaminada-, inicialmente circunscrita a tramos periféricos e inconexos, y hoy extendida y desplegada a lo largo de las vías públicas y accesible en todos los barrios de la ciudad. Ello permite de alguna forma a la naturaleza hacerse presente en los espacios urbanos donde había estado acotada. Pudiera concluirse que disponer de una instalación que promueve un transporte sostenible y que integra una actividad con beneficios medioambientales en el funcionamiento cotidiano de la ciudad, devuelve en alguna medida un cierto derecho a la naturaleza a la ciudadanía.

\section{A modo de conclusión}

El carril-bici de Sevilla disputa el espacio físico y virtual de la ciudad sujeta al control de las élites y reta al modelo urbano que concede prerrogativas excesivas al automóvil, objeto de la denuncia de Lefebvre (y de otros muchos autores). Su implantación física disminuyó el espacio 
destinado al aparcamiento de coches y, en ocasiones puntuales, al espacio de tránsito de la calzada (destinada primordialmente a la locomoción motorizada); su puesta en funcionamiento ha contribuido a disminuir el uso de vehículos a motor y ha pacificado - si bien no lo suficientemente- el tráfico de la ciudad. La disputa entre los dos modelos de movilidad puede observarse en la evolución física del carril-bici sevillano a lo largo de sus distintas fases de construcción: a medida que el capital simbólico del ciclismo urbano se fortalecía y sus posiciones contaban con mayor legitimidad en los espacios de decisión, se aceptaría más fácilmente dotar de mayor espacio a la infraestructura y superar el tabú de revertir espacios anteriormente dedicados al automóvil (Malpica, 2020, pp. 163-165). Al recordar la consideración de Lefebvre del espacio urbano como "lugar y terreno donde se enfrentan las estrategias" (1983, p. 93) entre un modelo de ciudad proyectado por los poderosos en función de principios tales como la funcionalidad y la mercantilización frente a los intereses de la sociedad urbana y la ciudad vivida (Lefebvre, 1978, p. 104; 1983, p. 159; 2013, p. 145), resulta oportuno observar en las diferentes facturas de las distintas fases de construcción del carril-bici sevillano las casi imperceptibles huellas de esta contienda.

Sin embargo, a pesar de todo lo expuesto, la infraestructura ciclista sevillana posee rasgos que podrían también percibirse como muestras de una implantación de la lógica institucional, como espacio concebido desde el poder, y ello se manifestaría en múltiples sentidos, algunos de los cuales vemos interesante reseñar. Así, el trazado de la red viaria ciclista sevillana por lo general respeta el espacio destinado en la calzada a la circulación (empleado prioritariamente por vehículos motorizados) y algunos de sus tramos tuvieron que plegarse a exigencias realizadas por el área municipal que detentaba las competencias de tráfico (favorable al predominio del automóvil sobre otras fórmulas de movilidad urbana). Al mismo tiempo, la implantación del carril-bici supone un obstáculo en mayor o menor grado para otras formas de locomoción sostenible, como la peatonal (una solución realmente eficaz de este problema solo podrá lograrse mediante una ambiciosa recuperación de un amplio porcentaje del espacio destinado hoy al automóvil, medida que solo de forma incipiente ha comenzado a implantarse muy recientemente). Para el propio ciclista, el carril-bici implica, al menos en ciertos aspectos, un proceso de acatamiento: las instituciones generaron una normativa específica de necesario cumplimiento para el tránsito en el carril-bici que supuso la introducción de obligaciones antes inexistentes —destinadas, además, a un colectivo cuyo desplazamiento en la ciudad se distinguía por estar desregulado- También supone, para el ciclista, una contención en el uso del espacio: el carril-bici que le concede una superficie propia supone al mismo tiempo la renuncia a toda la superficie, bien de forma expresa (así, según la normativa vigente, está prohibido que el ciclista use la calzada en vías donde exista un carril-bici) o bien inducida, como en el siguiente ejemplo expuesto por Hernández y Huerta:

En Sevilla por ejemplo, a excepción del casco histórico, los recorridos se ajustan y se diseñan en mayor o menor medida a una red de vías ciclistas que por lo general atiende a la conexión de zonas y servicios mediante las principales vías de la ciudad. Esto significa que, aunque no todo el recorrido se diseñe por el "carril bici", la existencia de una red de vías ciclistas interviene, de forma general, en ese trazado mental del itinerario (Hernández y Huerta, 2016, p 14). 
De hecho, también desde la matriz lefebvriana, podría analizarse la apropiación del espacio del carril-bici que se realiza a través de un uso contrario a la función de movilidad ciclista de dicha infraestructura: en este caso podríamos observar, entre otros ejemplos, el uso que del carril-bici hacen los peatones, los corredores, los usuarios de monopatín y patinete, los viandantes con maletas con ruedas o con carros de la compra, o los chatarreros que recolectan y transportan su mercancía ayudados por carritos de supermercado... agentes que ocupan el espacio del carril-bici desde tipos de movilidad carentes de prerrogativas y que resignifican con su práctica un espacio establecido desde la administración pública. ${ }^{3}$ Los propios ciclistas pueden resignificar el propio carril-bici mediante usos diferentes a lo planificado: como uno de los posibles ejemplos de ello, nótese que las vías ciclistas de un solo sentido son sistemáticamente utilizadas por muchos usuarios como carriles de doble sentido, solventando las limitaciones propias de la anchura limitada del carril con prácticas de negociación espacial. Al menos en algunos casos, estos usos contrarios a los fines de la infraestructura revelarán un inadecuado o mejorable diseño de las mismas.

A pesar de estas últimas consideraciones, al realizar un balance general desde todos los criterios lefebvrianos sopesados, la conclusión no podría ser en ningún caso que el carril-bici constriñe más el uso del espacio urbano de lo que lo libera: el éxito del carril-bici sevillano y su extendido uso por parte de la población de la ciudad sirve como una constatación del proceso de apropiación que ha supuesto, sino como una muestra más de que dicha obra pública merece ser calificada como un ejemplo de reforma que repercute en la producción de un nuevo espacio social más habitable. Hemos observado y contrastado en el análisis de las infraestructuras ciclistas de Sevilla que en el caso estudiado se cumplen las condiciones establecidas por Lefebvre en lo referente a la demanda de la infraestructura, los criterios de prospección y diseño, el carácter participativo del proceso de propuesta e implementación, el carácter desfavorecido de la movilidad a la que atendió, los procesos de apropiación — tanto espacial como política- en los que se basó y que a su vez generó y fortaleció, y el favorable impacto medioambiental que implicó su puesta en funcionamiento. De este modo, no debe considerarse que por defecto toda infraestructura ciclista sea consecuencia del "espacio representado" o "concebido" por técnicos y expertos en oposición al "espacio vivido", ya que el propio Lefebvre señalaba las condiciones, aun excepcionales, que permiten a la iniciativa institucional desvincularse del modelo funcionalista y mercantilista impuesto desde las élites, extremo del que el carril-bici de Sevilla parece ser un obvio ejemplo. La apropiación masiva - entusiasta, podríamos decir- por parte de un amplio número de la población sevillana de esta infraestructura innovadora puede verse como aval a la hora de considerar que esta intervención urbanística ha sabido desempeñar una función transformadora del espacio urbano.

No hemos de circunscribirnos aquí a meramente celebrar el éxito de una intervención pública determinada como es la red sevillana de carriles-bici —ni tampoco renunciar a hacerlo-. Pero el alcance final del estudio de este caso específico ha sido caracterizar sus logros, contrastar su aplicabilidad a los "preceptos" lefebvrianos, y, en tanto que dicho caso sea asimilable — siquiera en parte- a otras muchas infraestructuras públicas urbanas, contribuir a invalidar la ecuación según la cual toda obra pública municipal está necesariamente firmada con el sello coercitivo del Mercado y el Estado. Intervenciones urbanís-
3 Hemos excluido de esta enumeración a usuarios de patinetes eléctricos, de sillas de ruedas y de patines, por estar permitida por la normativa municipal su circulación en el carril-bici. También excluimos a los usuarios de coches — aparcados sobre el carril-bici- y motocicletas - aparcadas en el carril-bici o circulando por él一, por suponer tipos de movilidad que cuentan con las prerrogativas propias de la motorización, y, dada su posición de privilegio, no sería del todo adecuado, estrictamente, aplicarles el concepto de "apropiación" en la acepción lefebvriana del mismo. 
ticas como la aquí analizada deben considerarse, más bien, como herramientas para el cambio del modelo urbano: una valoración que no limita el efecto de dicha infraestructura a una modificación positiva o útil en el específico aspecto del tránsito de la ciudad, sino un elemento que contribuye a transformar la noción misma de ciudad que queremos disfrutar. El carril-bici sevillano, y otras iniciativas semejantes, constituyen en suma ejemplos en los que la planificación institucional y el espacio urbano reapropiado confluyen. Esta doble naturaleza de la infraestructura la sitúa en el plano de la consumación del llamamiento lefebvriano:

La estrategia del conocimiento no puede quedar aislada. Su meta es la práctica, o sea, en primer lugar una continua confrontación con la experiencia, y, en segundo lugar, la constitución de una práctica global, coherente, la práctica de la sociedad urbana (la práctica de la apropiación del tiempo y el espacio para el ser humano, modalidad superior de libertad) (Lefebvre, 1983, p. 147). 


\section{Referencias bibliográficas}

A Controamano (2008). 21 años en defensa de una movilidad más sostenible. Sevilla: A Contramano- Asamblea Ciclista. Recuperado el 20 de enero de 2021 de: http://www.acontramano.org/antigua/noticias / memoria-web-1.pdf.

Augé, Marc (2009). Elogio de la bicicleta. Barcelona: Gedisa.

Ayuntamiento de Sevilla (2010). Estudios sobre el uso de la bicicleta en la ciudad de Sevilla. Recuperado el 23 de enero de: http://www.acontramano.org/index.php?option=com_joomdoc\&task=document. download\&path=conteos-e-informes-del-uso-de-labici-en-sevilla\% 2F2009-conteo-de-ciclistas-en-noviembre-de-2009-y-estimacion-del-numero-de-desplazamientos-en-bicicleta\&Itemid $=62$.

Bourdieu, Pierre (1998). La distinción: criterios y bases sociales del gusto. Madrid: Taurus.

Bourdieu, Pierre (2008). El sentido práctico. Madrid: Siglo XXI.

Calvo Salazar, Manuel (2013). Movilidad sostenible en nuestras ciudades. Sevilla: Universidad de Sevilla.

Castells, Manuel (1986). La ciudad y las masas: sociología de los movimientos sociales urbanos. Madrid: Alianza Editorial.

Castells, Manuel (1988). La cuestión urbana. Madrid: Siglo XXI.

Castells, Manuel (2001). La Galaxia Internet. Reflexiones sobre Internet, empresa y sociedad. Barcelona: Plaza \& Janés.

Castillo Manzano, José I., y Sánchez Braza, Antonio (2013). Can anyone hate the bicycle? The hunt for an optimal local transportation policy to encourage bicycle usage. Environmental Politics, 22, 1010-1028. DOI: https://doi.org/10.1080/09644016.2012.740 936.

Costes, Laurence (2012). Del 'derecho a la ciudad' de Henri Lefebvre a la universalidad de la urbanización moderna. Urban, 2, 89-100. Recuperado el 20 de enero de 2021 de: http://polired.upm.es/index.php/urban/article/view/1495/1990

Gaviria, Mario (2006). La Bicicleta, ambientalmente perfecta. Auzolan, Hoja Informativa del Colegio Navarro de Sociólogos y Politólogos, 7, 5. Recuperado el 23 de enero de 2021 de: http:/ / www.colsocpona.org/ documentos/premios/2006/Bicicleta.pdf.

Gehl, Jan y Gemzøe, Lars (2002). Nuevos espacios urbanos. Barcelona: Gustavo Gili.

Gottdiener, Mark y Hutchison, Ray (2011). The New Urban Sociology. Boulder: Westview Press.

Hanson, Royce y Young, Garry (2008). Active living and biking. Tracing the Evolution of a Biking System in Arlington, Virginia. Journal of
Health Politics, Policy and Law, 33(3), 387-406. DOI: 10.1215/03616878-2008-002.

Hernández, Macarena y Huerta, Elena (2016). La ciudad desde la bicicleta. En Hernández, Macarena (Ed.), Bicitopias. Hacia una antropología de la movilidad urbana (pp. 11-28). Barcelona: Icaria.

Horton, Dave (2006). Environmentalism and the bicycle. Environmental Politics, 15(1), 41-58. DOI: 10.1080/09644010500418712.

Horton, Dave, Rosen, Paul y Cox, Peter (Eds.) (2007). Cycling and Society. Aldershot: Ashgate Publishing.

Kidder, Jeffrey L. (2009). Appropriating the city: space, theory, and bike messengers. Theory and Society, 38(3), 307-328. DOI: https://doi.org/10.1007/ s11186-008-9079-8.

Lefebvre, Henri (1978). El derecho a la ciudad. Barcelona: Península.

Lefebvre, Henri (1983). La revolución urbana. Madrid: Alianza Editorial.

Lefebvre, Henri (2006). Writings on cities. Cambridge: Blackwell.

Lefebvre, Henri (2013). La producción del espacio. Madrid: Capitán Swing.

Malpica, Pedro (2020). La influencia del campo social pro-bicicleta en el proceso de promoción del ciclismo urbano en Sevilla. Hábitat y Sociedad, 13, 151168. DOI: 10.12795/HabitatySociedad.2020.i13.09.

Marqués, Ricardo (2011). Sevilla: una experiencia exitosa de promoción de la movilidad en bicicleta en el Sur de Europa. Hábitat y Sociedad, 13, 107-130. DOI: 10.12795/HabitatySociedad.2011.i3.07.

Marqués, Ricardo, Hernández Herrador, Vicente, Calvo Salazar, Manuel y García Cebrián, José Antonio (2015). How infrastructure can promote cycling in cities: Lessons from Seville. Research in Transportation Economics-El selvier, 53(C), 31-44. DOI: 10.1016/j.retrec.2015.10.017.

Rodríguez Díaz, Álvaro (2008). El deporte en la construcción del espacio social. Madrid: Centro de Investigaciones Sociológicas.

Sanz, Alfonso (2008). Calmar el tráfico. Pasos para una nueva cultura de la movilidad urbana. Madrid: Centro de Publicaciones del Ministerio de Fomento.

Torres Elizburu, Roberto (2003). La bicicleta dentro de la movilidad urbana. El caso de Vitoria-Gasteiz. Lurralde. Investigación y espacio, 26, 103-121. Recuperado el 23 de enero de 2021 de: http:/ / www.ingeba.org/lurralde/lurranet/lur26/elizbu26/elizbu26.htm.

Weikart, Will (2006). Critical Multitude, War Machine: What the Left can Learn, and the Right May Have Already Learned, from a Bunch of Bicyclists. Situations: Project of the Radical Imagination, 1(2), 93-116. 
Malpica, Pedro (2021). Pedaleando con Lefebvre por el carrilbici de Sevilla: por qué no debemos presuponer que las infraestructuras públicas restringen necesariamente el derecho a la ciudad. Hábitat y Sociedad, 14, 263-286.

<https://doi.org/10.12795/HabitatySociedad.2021.i14.14>

$\bigcirc$ 